\title{
TRABALHO INTERMITENTE: \\ UMA BREVE ANÁLISE SOBRE SEUS EFEITOS NO REGIME GERAL DA PREVIDÊNCIA SOCIAL.
}

\author{
Mario Henrique de Souza Batista*
}

\section{RESUMO}

O presente artigo científico é resultado de uma investigação realizada acerca do novo contrato de trabalho intermitente, introduzido no Direito brasileiro, pela primeira vez, por intermédio da Lei 13.467, de 13 de julho de 2017 (vigência em 11 de novembro de 2017), conhecida como reforma trabalhista. O trabalho intermitente consiste em uma nova espécie de contratação regida pela Consolidação das Leis do Trabalho (CLT), pela qual o empregado será convocado para o trabalho de forma esporádica e receberá suas verbas contratuais apenas pelo período trabalhado, mas permanecendo com o contrato de trabalho ativo nos períodos de inatividade. Com o objetivo de apresentar algumas reflexões sobre os impactos que este contrato de trabalho poderá gerar nos aspectos gerais do Regime Geral da Previdência Social, buscou-se identificar como o instituto se amoldará no ordenamento jurídico pátrio e quais serão os seus impactos em temas como: inscrição e filiação do segurado; manutenção e perda da qualidade de segurado; períodos de carência; contribuição previdenciária; presunção de trabalho; entre outros. A presente pesquisa foi realizada com base em análises bibliográficas e na legislação.

Palavras-chave: Reforma trabalhista. Trabalho intermitente. Impacto no Regime Geral da Previdência Social.

\section{INTERMITTENT WORK: A BRIEF ANALYSIS OF ITS EFFECTS ON THE GENERAL SOCIAL SECURITY SYSTEM.}

\section{ABSTRACT}

This scientific article was the result of an investigation about the new intermitent empoyment contract, introduced in the brazilian law system, for the first time, through Law 13,467 of July 13, 2017 (effective on November 11, 2017), known as labor reform. Intermittent work consists of a new type of contract governed by the Consolidation of Labor Laws (CLT), where employee will be called up for work sporadically and will receive your contractual amounts only for the worked period, but remaining with the active employment

* Possui graduação em Direito pela Universidade Metodista de São Paulo. Pós-graduado (Lato Sensu) em Direito Previdenciário pela Faculdade Legale. Pós-graduando (Lato Sensu) em Direito e Processo do Trabalho pela Escola Paulista de Direito. Pós-graduando (Lato Sensu) em Direito Constitucional Aplicado pela Faculdade Legale. Pesquisador. Advogado. 
contract during periods of inactivity. In order to present some reflections on the impacts that this employment contract may have on the general aspects of the General Social Security Regime, it was sought to identify how the institute will conform to the national legal system and what will be its impacts on topics such as: insured's registration and affiliation; maintenance and loss of insured quality; grace periods; social security contribution; presumption of work; among others. This research was based on legal and bibliographic analysis and legislation.

Keywords: Labor reform; intermittent work; impact on the General Social Security Regime.

\section{INTRODUÇÃO}

A reforma trabalhista criou inúmeras novidades no direito do trabalho brasileiro, o que ainda é causa de intenso debate na doutrina.

O trabalho intermitente criado sob o argumento de legalização de atividades informais, foi uma dessas novidades, porém, a rapidez com que o projeto de lei tramitou pelo Congresso Nacional, em conjunto com a falta de debates com a sociedade, fez com que este contrato de trabalho fosse incluído no ordenamento jurídico sem muito zelo, dando ensejo, portanto, à insegurança jurídica.

Tanto é verdade que após poucos dias de vigência da lei, o contrato de trabalho intermitente foi profundamente alterado pela Medida Provisória $\mathrm{n}^{\mathrm{o}}$ 808, de 2017, que incluiu várias disposições nos artigos que tratam do tema, aprimorando o instituto.

Contudo, diante da fragilidade das Medidas Provisórias, que podem perder sua validade em casos de não conversão em lei (expressa ou tácita), a MP n 808/2017 casou ainda mais insegurança jurídica, vez que o seu prazo de conversão em lei transcorreu in albis, perdendo, consequentemente, sua vigência em 23 de abril de 2018.

Não bastasse, ainda existem três Ações Diretas de Inconstitucionalidade questionando a constitucionalidade do trabalho intermitente tramitando no Supremo Tribunal Federal sob os números ADI 5.806, ADI 5.826, ADI 5.829 e ADI 6.154.

Portanto, diante de tanta insegurança jurídica, torna-se necessário analisar os reflexos do trabalho intermitente nas regras gerais do regime geral da previdência social, uma vez que a legislação trabalhista afeta frontalmente as contribuições previdenciárias, bem como alguns requisitos essenciais para a concessão de prestações previdenciárias.

Deste modo, o presente artigo científico tem por objetivo contribuir com o debate, trazendo uma análise crítica sobre o ordenamento jurídico e doutrina sobre o tema.

Iniciando-se pelo sistema de Seguridade Social previsto na Constituição da República Federativa do Brasil de 1988, depois pelo sistema de Previdência Social pátrio até chegar à novel Lei n ${ }^{0}$ 13.467/2017 (Reforma Trabalhista), para, no final refletir sobre os possíveis impactos do novo instituto no regime geral de previdência social (RGPS). 


\section{A SEGURIDADE SOCIAL}

A seguridade social é um sistema solidário que visa dispensar proteção às pessoas em momentos de necessidade.

Este sistema está insculpido na Constituição da República Federativa do Brasil (CRFB), promulgada em 05 de outubro de 1988, no título VIII, capítulo II.

Entende-se que a seguridade social é um sistema de participação solidária, pois os artigos 194 e 195 da CRFB/1988 determinam que este sistema seja formado por um conjunto integrado de ações do Poder Público e da sociedade, bem como seja financiado por toda a sociedade, como segue:

Art. 194. A seguridade social compreende um conjunto integrado de ações de iniciativa dos Poderes Públicos e da sociedade, destinadas a assegurar os direitos relativos à saúde, à previdência e à assistência social. [...].

Art. 195. A seguridade social será financiada por toda a sociedade, de forma direta e indireta, nos termos da lei, mediante recursos provenientes dos orçamentos da União, dos Estados, do Distrito Federal e dos Municípios, [...]. (BRASIL, 1988).

Neste sentido, Santos (2014, p. 13) afirma que o “[...] dever constitucional imposto aos Poderes Públicos e à sociedade demonstra que a solidariedade é o fundamento da seguridade social".

Conforme previsto no § único do artigo 194 da CRFB/1988 a organização desse sistema cabe apenas ao Poder Público, que deverá pautar-se por sete objetivos previstos neste mesmo artigo.

São objetivos da seguridade social: universalidade da cobertura e do atendimento; uniformidade e equivalência dos benefícios e serviços às populações urbanas e rurais; seletividade e distributividade na prestação dos benefícios e serviços; irredutibilidade do valor dos benefícios; equidade na forma de participação no custeio; diversidade da base de financiamento; caráter democrático e descentralizado da administração, mediante gestão quadripartite, com participação dos trabalhadores, dos empregadores, dos aposentados e do governo nos órgãos colegiados.

Este sistema promove proteção social em três linhas distintas, denominadas saúde, assistência social e previdência social, todas elas com previsão constitucional.

A saúde, prevista nos artigos 196 a 200 da Carta Magna, é regida pela Lei 8.080/1990 que "Dispõe sobre as condições para a promoção, proteção e recuperação da saúde, a organização e o funcionamento dos serviços correspondentes e dá outras providências". (BRASIL, 1990).

Já a assistência social encontra base constitucional nos artigos 203 e 204 da CRFB/1988 e é regulada pela Lei 8.724/1993 (Lei Orgânica da Assistência Social), que conceitua o tema em seu artigo $1^{\circ}$ da seguinte forma:

Art. $1^{\circ}$ A assistência social, direito do cidadão e dever do Estado, é Política de Seguridade Social não contributiva, que provê os mínimos sociais, realizada através de um conjunto integrado de ações de iniciativa pública e da sociedade, para garantir o atendimento às necessidades básicas. (BRASIL, 1993). 
Os artigos 201 e 202 da CRFB/1988 regulam a previdência social. A Lei 8.212/1991 dispõe sobre o plano de custeio da seguridade social; a Lei 8.213/1991 dispõe sobre o plano de benefícios previdenciários do regime geral da previdência social, que por sua vez foi regulamentada pelo Decreto $n^{\circ} 3.048 / 1999$, que dispõe sobre o regulamento da previdência social.

Conforme as Leis 8.212/1991 (art. $3^{\circ}$ ) e 8.213/1991 (art. $1^{\circ}$ ), a finalidade da previdência social é garantir aos beneficiários meios necessários para a manutenção de sua própria subsistência em momentos de incapacidade, idade avançada, tempo de serviço, desemprego involuntário, encargos de família e reclusão ou morte daqueles de quem dependiam economicamente, senão vejamos:

Lei 8.212/1991 - Art. $3^{\circ}$ A Previdência Social tem por fim assegurar aos seus beneficiários meios indispensáveis de manutenção, por motivo de incapacidade, idade avançada, tempo de serviço, desemprego involuntário, encargos de família e reclusão ou morte daqueles de quem dependiam economicamente. (BRASIL, 1991).

Lei 8.213/1991 - Art. $1^{\circ}$ A Previdência Social, mediante contribuição, tem por fim assegurar aos seus beneficiários meios indispensáveis de manutenção, por motivo de incapacidade, desemprego involuntário, idade avançada, tempo de serviço, encargos familiares e prisão ou morte daqueles de quem dependiam economicamente. (BRASIL, 1991).

O artigo $2^{\circ}$ da Lei 8.080/90 estabelece que a saúde é um direito de todos e dever do Estado, portanto, pode-se concluir que todas as pessoas físicas terão direito à saúde, independente de contribuições para seu custeio, o que é o oposto da previdência social que assegura proteção apenas às pessoas físicas que contribuíram para o sistema de custeio, conforme artigo $1^{\circ}$ da Lei 8.213/1991. Diferente das linhas que lhe antecederam, a assistência social será devida apenas às pessoas físicas que de fato precisarem do auxílio, independente de contribuições para o sistema.

Por fim, ressalta-se que para análise do presente estudo, serão levadas em consideração apenas as regras que regem a previdência social, uma vez que é o sistema que regulamenta os benefícios que serão estudados mais à frente.

\section{A PREVIDÊNCIA SOCIAL}

Conforme mencionado no capítulo que versa sobre a seguridade social, esta busca alcançar seus objetivos por três linhas distintas, que são: saúde, previdência social e assistência social.

Para servir à seguridade social de forma efetiva a previdência social deve além de respeitar a CRFB/1988, seguir princípios próprios e regras específicas presentes na legislação infraconstitucional, o que serão expostos de forma sucinta neste capítulo.

O sistema previdenciário previsto nos artigos 201 e 202 da CRFB/1988 inicialmente se subdivide em duas espécies, a primeira trata dos regimes públicos e a segunda do regime privado. 
Conforme depreende-se do artigo 201 da Carta Magna, o regime público da previdência social se ramifica em três subespécies, denominadas como regime geral de previdência social (RGPS), regime dos servidores públicos civis e regimes dos servidores militares.

Já o artigo 202 da CRFB/1988 cria a figura do regime previdenciário privado, que prevê a previdência complementar.

No presente estudo será abordado apenas o regime geral de previdência social, razão pela qual os demais regimes não serão objeto de análise.

Segundo os ensinamentos de Marisa Ferreira dos Santos:

O RGPS tem normatização infraconstitucional pela Lei no 8.212 (Plano de Custeio da Seguridade Social - PCSS) e Lei no 8.213 (Plano de Benefícios da Previdência Social - PBPS), ambas de 24-7-1991, regulamentadas pelo Decreto no 3.048, de 6-5-1999 (Regulamento da Previdência Social - RPS), com suas alterações posteriores. (SANTOS, 2014, p. 83).

A Lei $n^{\circ} 8.213 / 1991$ (art. $2^{\circ}$ ) e o Decreto n $3.048 / 1999$ (art. $4^{\circ}$ ) dispõem sobre os princípios e objetivos da previdência social, que são: universalidade de participação nos planos previdenciários; uniformidade e equivalência dos benefícios e serviços às populações urbanas e rurais; seletividade e distributividade na prestação dos benefícios; cálculo dos benefícios considerando-se os salários de contribuição corrigidos monetariamente; irredutibilidade do valor dos benefícios de forma a preservar-lhes o poder aquisitivo; valor da renda mensal dos benefícios substitutos do salário-de-contribuição ou do rendimento do trabalho do segurado não inferior ao do salário mínimo; previdência complementar facultativa, custeada por contribuição adicional; caráter democrático e descentralizado da gestão administrativa, com a participação do governo e da comunidade, em especial de trabalhadores em atividade, empregadores e aposentados.

Neste sentido, imperioso mencionar os ensinamentos de Antonio Bonival Camargo, que afirma que os princípios:

[...] não se revestem de palavras, mas de ideias. Não são cogentes, mas se impõe pela razão; não obrigam pela imposição, mas pela nobreza do convencimento. Os princípios constituem a alma do corpus juridicus. De uma ou outra forma fazem-se sempre presentes e atuantes na lei. Estão para a lei, como a alma está para o corpo. As normas, as leis, as regras se alteram de acordo com os ventos políticos, e pelas influências filosóficas, os princípios se fazem inalterados. (CAMARGO, 2000, p. 30).

Com base nesses princípios, a previdência social deve fornecer meios de manutenção para seus beneficiários nas hipóteses previstas no artigo $1^{\circ}$ da Lei $n^{\circ}$ 8.213/1991, como segue:

Art. $1^{\circ}$ A Previdência Social, mediante contribuição, tem por fim assegurar aos seus beneficiários meios indispensáveis de manutenção, por 
motivo de incapacidade, desemprego involuntário, idade avançada, tempo de serviço, encargos familiares e prisão ou morte daqueles de quem dependiam economicamente. (BRASIL, 1991).

Com efeito, o Decreto 3.048/1999 prevê que o RGPS fornecerá prestações a seus beneficiários em forma de benefícios e serviços. Prestações estas que estão previstas no artigo 25 do referido Decreto que assim dispõe:

Art. 25. O Regime Geral de Previdência Social compreende as seguintes prestações, expressas em benefícios e serviços:

I - quanto ao segurado:

a) aposentadoria por invalidez;

b) aposentadoria por idade;

c) aposentadoria por tempo de contribuição;

d) aposentadoria especial;

e) auxílio-doença;

f) salário-família;

g) salário-maternidade; e

h) auxílio-acidente;

II - quanto ao dependente:

a) pensão por morte; e

b) auxílio-reclusão; e

III - quanto ao segurado e dependente: reabilitação profissional. (BRASIL, 1999).

Imperioso se faz, portanto, analisar o trabalho intermitente, criado com a promulgação da Lei 13.467/2017, conhecida popularmente como, reforma trabalhista, para entender quais serão seus efeitos no sistema previdenciário.

\section{A REFORMA TRABALHISTA (LEI No 13.467/2017)}

Em 13 de julho de 2017 foi promulgada a Lei $n^{\circ} 13.467$, que alterou o Decreto-Lei $n^{\circ} 5.452$ de $1^{\circ}$ de maio de 1944 consolidando leis do trabalho. Esta lei modificou profundamente o direito do trabalho, com consequentes reflexos em diversos ramos do direito e principalmente no direito previdenciário, que mantém clara interligação com o direito do trabalho e com o trabalho propriamente dito.

Embora o maior impacto tenha ocorrido na Consolidação das Leis do Trabalho (CLT), a Reforma Trabalhista alterou também as Leis $\mathrm{n}^{\circ} 6.019$, de 03 de janeiro de 1974, nº 8.036, de 11 de maio de 1990, e 8.212, de 24 de julho de 1991.

Após o transcurso do período de vacatio legis de 120 dias (art. $6^{\circ}$ da Lei $\mathrm{n}^{\circ}$ 13.467/2017), a Reforma Trabalhista passou a vigorar em todo o país no dia 11 de novembro de 2017, trazendo em seus artigos disposições de direito material e processual do trabalho. Quanto a este período curto de vacatio legis, Homero Batista Mateus da Silva pontua que:

[...] o tempo de descanso para mudanças tão profundas na legislação 
brasileira costuma ser de um ano - como ocorreu com as alterações do processo civil em 2015 e do direito civil em 2002 -, mas a reforma trabalhista concedeu apenas 120 dias para a sociedade se adequar. (SILVA, 2017).

Em suma, temas como jornada de trabalho, intervalo para refeição e descanso, condições do trabalho da empregada gestante, divisão de férias, rescisão contratual, justiça gratuita, ônus da prova, petição inicial, entre outros, sofreram alterações dos mais variados níveis. E temas como, prescrição intercorrente, dano extrapatrimonial, dano existencial, contagem de prazos em dias úteis, honorários de sucumbência, litigância de má-fé, rescisão contratual por mútuo acordo, homologação judicial de acordo extrajudicial, prevalência da negociação coletiva sobre a legislação, teletrabalho, trabalho intermitente, dentre tantos outros temas de suma importância, foram incorporados à Consolidação das Leis do Trabalho.

Na visão de Maurício Godinho Delgado e Gabriela Neves Delgado:

A reforma trabalhista implementada no Brasil [...] desponta por seu direcionamento claro em busca do antigo papel do Direito na História como instrumento de exclusão, segregação e sedimentação da desigualdade entre pessoas humanas e grupos sociais. (DELGADO M; DELGADO G, 2017, p. 39/40).

Não bastasse a aprovação da Reforma Trabalhista, esta foi modificada após poucos dias de vigência pela Medida Provisória $n^{\circ}$ 808, de 14 de novembro de 2017. Contudo esta Medida Provisória teve seu prazo de vigência encerrado em 23 de abril de 2018, conforme Ato Declaratório n ${ }^{\circ} 2$ de 24 de abril de 2018, retornando a Lei 13.467/2017 seu status quo ante.

Não obstante outros pontos da reforma trabalhista possam, de algum modo, refletir no direito previdenciário, no presente artigo apenas os reflexos gerados pelo trabalho intermitente serão analisados, levando-se em consideração que este tema é umas das maiores inovações criadas pela Lei da Reforma Trabalhista, como afirma Homero Batista Mateus da Silva:

A inserção do art. 452-A ao corpo da CLT, prevendo uma modalidade de contrato de trabalho intermitente, representa uma das grandes inovações da reforma de 2017, certamente a ser inserida na lista das quatro ou cinco maiores quebras de paradigmas. (SILVA, 2017).

Deste modo, o próximo capítulo tem por objetivo entender o instituto criado pela novel Lei da Reforma Trabalhista, para que mais adiante seja possível refletir sobre os seus reflexos em alguns pontos do Regime Geral da Previdência Social.

\section{V.O TRABALHO INTERMITENTE}

O trabalho intermitente trata-se de nova espécie de contrato de trabalho, que, após o advento da Lei $\mathrm{n}^{\circ} 13.467 / 2017$, se junta com as demais espécies de 
contrato de trabalho, como os contratos de trabalho por prazo determinado, indeterminado e o contrato de trabalho temporário, conforme se extrai do artigo 443 da CLT, que assim dispõe:

Art. 443 - O contrato individual de trabalho poderá ser acordado tácita ou expressamente, verbalmente ou por escrito, por prazo determinado ou indeterminado, ou para prestação de trabalho intermitente. (BRASIL, 1943).

Nas palavras de Martins e Pedreira (2017, p. 42) o "[t]rabalho intermitente é sinônimo de trabalho não contínuo, ou seja, com alternância entre períodos de atividade e inatividade".

E em um esforço conceitual o legislador insere no art. 443 da CLT o $\S 3^{\circ}$ que assim dispõe (SILVA, 2017):

$\S 3^{\circ}$. Considera-se como intermitente o contrato de trabalho no qual a prestação de serviços, com subordinação, não é contínua, ocorrendo com alternância de períodos de prestação de serviços e de inatividade, determinados em horas, dias ou meses, independentemente do tipo de atividade do empregado e do empregador, exceto para os aeronautas, regidos por legislação própria. (BRASIL, 1943).

Portanto, o contrato ora analisado se diferencia das demais espécies de contrato de trabalho, em razão de englobar os períodos de atividade e inatividade do empregado, sem que o período de inatividade seja considerado tempo à disposição do empregador, conforme $\$ 5^{\circ}$ do art. 452-A da CLT, senão vejamos:

$\S 5^{\circ}$. O período de inatividade não será considerado tempo à disposição do empregador, podendo o trabalhador prestar serviços a outros contratantes. Incluído pela Lei $\mathrm{n}^{\circ} 13.467$, de 2017. (BRASIL, 1943).

Nas palavras de DELGADO M e DELGADO G (2017, p. 154): “[...] tenta criar conceito novo: a realidade do tempo à disposição do empregador, porém sem efeitos jurídicos do tempo à disposição".

No mesmo sentido, SILVA (2017) é incisivo ao afirmar que “[...] o âmago do dispositivo está no $\S 5^{\circ}$, que afirma categoricamente que o período de chamado não é tempo à disposição do empregado e, portanto, não assegura salário, benefícios ou encargos".

Ressalta-se por oportuno, que grande parte dos reflexos no Regime Geral da Previdência Social será gerada em decorrência do $\$ 5^{\circ}$ mencionado alhures, uma vez que durante os períodos de inatividade o contrato de trabalho intermitente não surtirá efeitos jurídicos, o que será exposto em capítulo próprio.

Por outro lado, conservou-se a subordinação ao empregador, característica que está prevista no art. $3^{\circ}$ da CLT como requisito para ser qualificado como empregado, ou seja, o contrato de trabalho intermitente é caracterizado pela presta- 
ção de serviço por pessoa física à pessoa física ou jurídica, de forma onerosa e com subordinação.

Em suma, depreende-se do art. 452-A da CLT - caput, §§ e incisos - a obrigatoriedade que este contrato seja firmado por escrito, com menção expressa ao valor da hora de trabalho, que terá que obedecer dois pisos salariais: o primeiro sendo a regra geral, que é o valor-hora do salário mínimo e o segundo piso salarial é o valor - hora dos demais empregados que exercem a mesma função e no mesmo estabelecimento, com objetivo de não ferir preceitos constitucionais, tais como:

Art. $7^{\circ}$ São direitos dos trabalhadores urbanos e rurais, além de outros que visem à melhoria de sua condição social:

IV - salário mínimo, fixado em lei, nacionalmente unificado, capaz de atender a suas necessidades vitais básicas e às de sua família com moradia, alimentação, educação, saúde, lazer, vestuário, higiene, transporte e previdência social, com reajustes periódicos que lhe preservem o poder aquisitivo, sendo vedada sua vinculação para qualquer fim;

V - piso salarial proporcional à extensão e à complexidade do trabalho. (BRASIL, 1988).

O mesmo artigo ainda determina que o empregador deverá convocar o empregado com três dias corridos de antecedência (Art. 452-A, $\$ 1^{\circ}$ ) e o empregado terá um dia útil para firmar expressamente o aceite da prestação de serviço $\left(\$ 2^{\circ}\right)$, sendo que a negativa do empregado (expressa ou por decurso do prazo mencionado) não caracterizará insubordinação $\left(\$ 3^{\circ}\right)$.

A parte que não cumprir com suas obrigações no dia da prestação do serviço, sem justificação - seja o empregado não comparecendo ou o empregador desistindo da prestação de serviço do empregado -, será devida uma multa à parte prejudicada, no importe de $50 \%$ da remuneração que seria devida pelos serviços, que deverá ser paga no prazo de trinta dias $\left(\S^{\circ}\right)$.

Encerrado o período de prestação de serviço, que poderá ser de horas, dias ou meses (art. $443, \S 3^{\circ}$ ), o empregador deverá pagar ao empregado a remuneração (Art. $452-\mathrm{A}, \S 6^{\circ}$, inciso I), férias proporcionais com o acréscimo de $1 / 3$ (Art. 452-A, $\S 6^{\circ}$, inciso II), décimo terceiro salário proporcional (Art. 452-A, $\$ 6^{\circ}$, inciso III), descanso semanal remunerado (Art. 452-A, $\S 6^{\circ}$, inciso IV) e adicionais legal (Art. 452-A, $\S 6^{\circ}$, inciso $\mathrm{V}$ ), em recibo de pagamento discriminando verba a verba (Art. 452-A, $\$ 7^{\circ}$ ).

O empregador deverá reter as contribuições previdenciárias e tributárias do empregado e repassar para o órgão correto $\left(\$ 8^{\circ}\right)$ e após o período aquisitivo de doze meses o empregado terá direito a gozar férias $\left(\S 9^{\circ}\right)$.

O presente instituto sofreu grande alteração pela Medida Provisória no 808 de 2017, levando-se em consideração que a MP acabou por incluir mais detalhes sobre o trabalho intermitente, o que será analisado no próximo tópico, em separado, uma vez que esta MP perdeu sua validade, conforme já mencionado. 


\section{I UMA BREVE ANÁLISE SOBRE O TRABALHO INTERMITENTE DURANTE A VIGÊNCIA DA MEDIDA PROVISÓRIA No 808/2017.}

O contrato de trabalho intermitente é uma figura nova no direito do trabalho brasileiro sem nenhum precedente e por esta razão a Medida Provisória $\mathrm{n}^{\circ}$ $808 / 2017$, alterou quase que completamente o tema, introduzindo detalhes importantes, ou seja, a MP 808/17 aprimorou o instituto prevendo regras para um número maior de situações nos novos artigos 452-A, 452-B, 452-C, 452-D, 452-E, 452-F, 452-G e 452-H, todos eles acompanhados de parágrafos e incisos.

Ocorre que, conforme já mencionado, a Medida Provisória perdeu sua validade e com isso as regras do trabalho intermitente voltaram a serem apenas as previstas no art. 452-A da CLT, pois, segundo MORAES (2004, p. 575), "[a] decadência da Medida Provisória, pelo decurso do prazo constitucional, opera a desconstituição, com efeitos retroativos, dos atos produzidos durante sua vigência".

Dentre tantas mudanças, destaca-se a previsão expressa de registro do contrato em CTPS; novo prazo para aceite do serviço pelo empregado, que passou de um dia útil para vinte e quatros horas; parcelamento do gozo das férias em até três períodos; auxílio-doença desde o primeiro dia da incapacidade, salário-maternidade diretamente pela previdência social; rescisão automática do contrato de trabalho após um ano sem convocações pelo empregador; aviso prévio necessariamente indenizado e pago pela metade; liberação de $80 \%$ do FGTS e multa de $20 \%$ sobre os valores depositados; impossibilidade de acesso ao benefício seguro desemprego; e período de quarentena para empregados com contrato por prazo indeterminado.

Fato é que a Medida Provisória deixou de vigorar no dia 23 de abril de 2018, causando grande insegurança jurídica, para empregados e empregadores.

\section{OS EFEITOS DO TRABALHO INTERMITENTE NAS REGRAS DO REGIME GERAL DA PREVIDÊNCIA SOCIAL \\ O período de inatividade do empregado e a possibilidade de períodos sem re-} muneração (remuneração zero), sem sombras de dúvidas, são os pontos de maior relevância e impacto do trabalho intermitente no direito previdenciário, ou seja, consequentemente esses dois pontos causarão efeitos no regime geral de previdência social.

Este entendimento se justifica pelo fato de o trabalhador intermitente ser considerado segurado obrigatório da previdência social, como segurado empregado, que tem por característica primordial o trabalho remunerado não eventual, conforme art. 11, inciso I, alínea "a" da Lei no 8.213/1991, senão vejamos:

Art. 11. São segurados obrigatórios da Previdência Social as seguintes pessoas físicas:

I - como empregado:

a) aquele que presta serviço de natureza urbana ou rural à empresa, em caráter não eventual, sob sua subordinação e mediante remuneração, inclusive como diretor empregado. (BRASIL, 1991). 
Neste sentido, o art. $9^{\circ}, \S 4^{\circ}$ do Decreto 3.048, de 06 de maio de 1999, que regulamenta a previdência social estabelece que o trabalho caracterizado como não eventual é aquele que tem relação direta ou indireta com a atividade normal do empregador, como segue:

$\S 4^{\mathrm{O}}$ Entende-se por serviço prestado em caráter não eventual aquele relacionado direta ou indiretamente com as atividades normais da empresa.

Portanto, entender como se dará a relação entre os períodos de inatividade e remuneração zero do trabalhador intermitente com os requisitos do regime geral da previdência social (como a inscrição; filiação; qualidade de segurado; carência; e presunção de trabalho), se faz de suma importância.

\section{VI.I DA INSCRIÇÃO, FILIAÇÃO, MANUTENÇÃO E PERDA DA QUALIDADE DE SEGURADO}

Inscrição e filiação no direito previdenciário são institutos muito próximos, mas que não se confundem. Neste sentido, vale ressaltar que a inscrição é um ato meramente formal de cadastro e entrega de documentos, que será realizado pelo segurado, quando este for facultativo e pelo empregador quando for caso de segurado empregado.

Esta diferenciação entre segurado facultativo e segurado empregado no ato da inscrição se dá porque o empregador no momento da contratação do segurado empregado o inscreve automaticamente no sistema da previdência social, mas, isso não ocorre com o segurado facultativo, uma vez que este só será inscrito por vontade própria, já que não tem a obrigação de contribuir para o sistema de custeio da seguridade social previsto na Lei no 8.212/1991.

Já a filiação, na definição de Fábio Zambitte Ibrahim é:

[...] o vínculo jurídico que se estabelece entre o segurado e o RGPS. Decorre automaticamente da atividade remunerada, ou seja, no momento em que uma pessoa iniciar o exercício de alguma atividade remunerada, ipso facto, estará filiada à previdência social [...]. (IBRAHIM, 2011, p. 173).

Neste sentido, o artigo 20 e seus $\S \S$ do Decreto $n^{\circ} 3.048 / 1999$ estabelecem que a filiação decorre do exercício de atividade remunerada para segurados obrigatórios e da inscrição com o primeiro pagamento em dia para o segurado facultativo, gerando, consequentemente, direito e obrigações entre as partes, como segue:

Art. 20. Filiação é o vínculo que se estabelece entre pessoas que contribuem para a previdência social e esta, do qual decorrem direitos e obrigações.

§1ํㅡ A filiação à previdência social decorre automaticamente do exercício de atividade remunerada para os segurados obrigatórios, observado o disposto no $\S 2$ 으, e da inscrição formalizada com o pagamento da primeira contribuição para o segurado facultativo. 
§ 2ㅇ A filiação do trabalhador rural contratado por produtor rural pessoa física por prazo de até dois meses dentro do período de um ano, para o exercício de atividades de natureza temporária, decorre automaticamente de sua inclusão na GFIP, mediante identificação específica. (BRASIL, 1999).

Portanto, com o objetivo de delimitar o assunto tratado, vale especificar que o trabalhador intermitente, deve ser considerado como segurado empregado, ou seja, de filiação obrigatória ao RGPS, enquadrado pelo artigo 11, inciso I, alínea $a$ da Lei n ${ }^{\circ} 8.213 / 1991$, com inscrição realizada de forma automática por seu primeiro empregador (caso este ainda não esteja inscrito).

Imperioso consignar que, na visão de Fábio Zambitte Ibrahim, com a expressão "exercício de atividade remunerada" o que deve ser levado em consideração, no caso de segurado empregado, é o momento da contratação e não o momento efetivo das atividades, como segue:

Cabe ressaltar que o início da atividade remunerada não coincide, ne-
cessariamente, com o efetivo começo do trabalho, mas sim quando está
pactuada a prestação de serviço, ainda que em outro momento ou o
pagamento seja em outra data. Assim, por exemplo, para o empregado,
a conformação da contratação pelo empregador já efetiva a filiação ao
RGPS. (IBRAHIM, 2011, p. 173).

Deste modo, é possível defender que após ser contratado, o trabalhador intermitente se filia automaticamente ao RGPS, mesmo essa contratação ocorrendo sem nenhuma convocação para o trabalho, ou seja, nos momentos de inatividade do empregado e independente de contribuição, adquirindo, portanto, qualidade de segurado.

No entanto, os períodos de inatividade no trabalho intermitente poderão se estender por um longo lapso temporal, colocando o empregado intermitente em risco. Para SANTOS (2017, p. 191), “a regra geral é a de que a qualidade de segurado se mantém enquanto forem pagas as contribuições previdenciárias para o custeio do RGPS" e nos termos da Lei 13.467/2017 só existirão contribuições previdenciárias nos períodos de trabalho efetivo, conforme depreende-se do artigo $452-\mathrm{A}, \S 8^{\circ}$, como segue:

§ 8o $O$ empregador efetuará o recolhimento da contribuição previdenciária e o depósito do Fundo de Garantia do Tempo de Serviço, na forma da lei, com base nos valores pagos no período mensal e fornecerá ao empregado comprovante do cumprimento dessas obrigações. (BRASIL, 1943).

Na redação dada pela Medida Provisória $n^{\circ} 808$, texto atualmente sem vigência, o entendimento era o mesmo: 
Art. 452-H. No contrato de trabalho intermitente, o empregador efetuará o recolhimento das contribuições previdenciárias próprias e do empregado e o depósito do FGTS com base nos valores pagos no período mensal e fornecerá ao empregado comprovante do cumprimento dessas obrigações, observado o disposto no art. 911-A. (BRASIL, 1943).

A interpretação mais lógica a se chegar é a que o empregado intermitente sempre que estiver nos períodos de inatividade, entrará, por consequência da falta de atividade remunerada e contribuições previdenciárias, nos períodos de graça, como são conhecidos os períodos em que o segurado não contribui para o sistema da seguridade social, mas mantém sua qualidade de segurado, nos termos do artigo 15 da Lei no 8.213/1991 e do artigo 13 do Decreto n ${ }^{\circ} 3.048 / 1999$.

O artigo 15 da Lei $n^{\circ} 8.213 / 1991$ prevê algumas hipóteses em que o segurado manterá a qualidade de segurado, independentemente de contribuições. Dentre essas possibilidades apenas duas se enquadram na realidade do contrato intermitente, que são as previstas no inciso II e no $\S 1^{\circ}$, que estabelecem o que segue:

Art. 15. Mantém a qualidade de segurado, independentemente de contribuições:

II - até 12 (doze) meses após a cessação das contribuições, o segurado que deixar de exercer atividade remunerada abrangida pela Previdência Social ou estiver suspenso ou licenciado sem remuneração;

$\S 1^{\circ} \mathrm{O}$ prazo do inciso II será prorrogado para até 24 (vinte e quatro) meses se o segurado já tiver pago mais de 120 (cento e vinte) contribuições mensais sem interrupção que acarrete a perda da qualidade de segurado. (BRASIL, 1991).

Deste modo, o segurado empregado (intermitente) terá uma segurança previdenciária de até 12 meses após a cessação da contribuição (contabilizada na forma do $\S 4^{\circ}$ do mesmo artigo), e, apenas nos casos onde o segurado já tiver efetuado mais de 120 contribuições essa segurança será elevada por mais 12 meses, chegando ao limite máximo de 24 meses de proteção sem contribuições. Portanto, é possível concluir, hipoteticamente, que passados 24 meses sem ser convocado para a prestação de serviço, este empregado perderá sua qualidade de segurado, mesmo com seu contrato de trabalho estando ativo.

Ressalta-se por oportuno que, por não estar desempregado, o segurado não terá a possibilidade de se valer dos períodos de graça previstos no $\$ 2^{\circ}$ do artigo 15 da lei mencionada alhures. Por esta razão, Homero Batista Mateus da Silva entende ser necessária a estipulação, por lei, de limite máximo de tempo para a inatividade do segurado, senão vejamos:

[...] fixação de algum teto máximo de permanência sem ser chamado; além de ser zero, o contrato não pode ser eterno; o governo federal sinaliza favoravelmente a uno de prazo máximo para o empregador manter o contrato-intermitente na gaveta. (SILVA, 2017). 
Após a entrada em vigor da Medida Provisória $n^{\circ} 808$ este problema havia encontrado uma resposta, pois o artigo 452-D previa exatamente este limite de um ano de inatividade, sob pena de rescisão contratual automática no fim do prazo, como segue:

Art. 452-D - Decorrido o prazo de um ano sem qualquer convocação do empregado pelo empregador, contado a partir da data da celebração do contrato, da última convocação ou do último dia de prestação de serviços, o que for mais recente, será considerado rescindido de pleno direito o contrato de trabalho intermitente. (BRASIL, 1943).

Entretanto, conforme já mencionado em capítulos anteriores, a Medida Provisória $\mathrm{n}^{\circ} 808$ não está em vigor por decurso de seu prazo sem que esta fosse convertida em lei, e por este motivo o segurado de contrato de trabalho intermitente correrá, por consequência lógica, o risco de perder sua qualidade de segurado mesmo com o contrato estando ativo, afrontando o princípio da igualdade. (Art. $7^{\circ}$, inciso XXXI da CRFB/88 e Art. 461 da CLT).

\section{VI.II DO PERÍODO DE CARÊNCIA. DA OBRIGAÇÃO DO EMPRE- GADOR DE DESCONTAR E RECOLHER AS CONTRIBUIÇÕES PRE- VIDENCIÁRIAS DE SEUS EMPREGADOS. DA PRESUNÇÃO DE TRABALHO.}

A Lei $n^{0} 8.213 / 91$ reserva seção especial para os períodos de carência que estão nos artigos 24 a 27-A. No mesmo sentido os artigos de 26 a 30 do Decreto ${ }^{\circ}$ 3.048/99 dispõem sobre o tema.

Segundo Fábio Zambitte Ibrahim:

Período de carência é o número de contribuições mensais mínimas que o segurado deve efetivar para ter direito a benefício, consideradas a partir do transcurso do primeiro dia dos meses de suas competências. (IBRAHUM, 2011, p. 541).

Para cada benefício a Lei prevê um período de carência específico e em alguns casos o benefício será concedido sem a necessidade de cumprimento de período de carência.

Neste sentido, o artigo 29 do Decreto $n^{\circ}$ 3.048/99 estabelece um período de carência de 12 contribuições mensais para a concessão de auxílio-doença e aposentadoria por invalidez; 180 contribuições mensais para as aposentadorias por idade, tempo de contribuição e especial; e 10 contribuições mensais para o salário maternidade de seguradas contribuinte individual, especial e facultativa.

Entretanto, a concessão de prestações previdenciárias como pensão por morte, auxílio-reclusão, salário família, auxílio-acidente, salário maternidade para a segurada empregada, auxílio-doença e aposentadoria por invalidez decorrentes de acidente de trabalho, não dependem de cumprimento de períodos de carência nos termos do artigo 30 do Decreto mencionado. 
Nota-se que, para o sistema previdenciário, o que será levado em consideração para efeitos de carências serão as contribuições devidamente efetuadas. Portanto, forçoso concluir que o segurado que se ativar em contrato de trabalho intermitente terá sérios problemas, uma vez que essa modalidade de contrato não estipula remuneração todos meses e não garante o pagamento de um salário mínimo, podendo chegar a períodos sem nenhuma remuneração, como explica Homero Batista Mateus da Silva:

Entretanto - e sempre há uma conjunção adversativa na reforma de 2017 - o art. 452-A oficializa não somente o "bico", mas também o contrato-zero. [...] o âmago do dispositivo está no $\S 5^{\circ}$, que afirma categoricamente que o período desprovido de chamado não é tempo à disposição do empregador e, portanto, não assegura salário, benefícios ou encargos.

A figura é assustadora porque poderá resolver os índices de desemprego do Brasil sem que as pessoas tenham renda assegurada [...].

O conceito de salário-mínimo dificilmente se coaduna com o contrato-zero, porque submete ao trabalhador a um fator aleatório imponderável. Amarrado ao contrato-zero, ele não pode pleitear o seguro desemprego e ao mesmo tempo não sabe se terá renda ou benefício previdenciário. (SILVA, 2017).

Sem receber remuneração nos períodos de inatividade, este segurado não conseguirá contribuir mensalmente, logo, não conseguirá cumprir os períodos de carência e consequentemente não terá acesso ao acervo de benefícios previdenciários, mesmo trabalhando legalmente, o que também afronta o princípio da igualdade.

Outrossim, não logrando êxito em conseguir atividades suficientes que the garantam uma remuneração compatível com no mínimo salário mínimo nacional, este segurado terá que complementar a contribuição previdenciária o que comprometerá ainda mais sua remuneração, pois, conforme o artigo $28, \S 3^{\circ}$ da Lei 8.212/91, o salário mínimo nacional será o piso, ou seja, será o valor mínimo do salário de contribuição, senão vejamos:

Art. 28. Entende-se por salário-de-contribuição:

$\S 3^{\circ} \mathrm{O}$ limite mínimo do salário-de-contribuição corresponde ao piso salarial, legal ou normativo, da categoria ou, inexistindo este, ao salário mínimo, tomado no seu valor mensal, diário ou horário, conforme o ajustado e o tempo de trabalho efetivo durante o mês. (BRASIL, 2017).

A Medida Provisória $n^{\circ}$ 808/17 alterou a CLT para introduzir em seu texto o artigo 911-A, já extinto, que assim estabelecia:

Art. 911-A. O empregador efetuará o recolhimento das contribuições previdenciárias próprias e do trabalhador e o depósito do FGTS com base nos valores pagos no período mensal e fornecerá ao empregado comprovante do cumprimento dessas obrigações. 
$\S 1^{\circ}$ Os segurados enquadrados como empregados que, no somatório de remunerações auferidas de um ou mais empregadores no período de um mês, independentemente do tipo de contrato de trabalho, receberem remuneração inferior ao salário mínimo mensal, poderão recolher ao Regime Geral de Previdência Social a diferença entre a remuneração recebida e o valor do salário mínimo mensal, em que incidirá a mesma alíquota aplicada à contribuição do trabalhador retida pelo empregador.

$\S 2^{\circ} \mathrm{Na}$ hipótese de não ser feito o recolhimento complementar previsto no $\S 1^{\circ}$, o mês em que a remuneração total recebida pelo segurado de um ou mais empregadores for menor que o salário mínimo mensal não será considerado para fins de aquisição e manutenção de qualidade de segurado do Regime Geral de Previdência Social nem para cumprimento dos períodos de carência para concessão dos benefícios previdenciários. (BRASIL, 1943).

Não bastasse, a Receita Federal do Brasil expediu o Ato Declaratório Interpretativo RFB n 6 $^{1}$, publicado em 27 de novembro de 2017 (com força de norma complementar, nos termos do artigo 100, inciso I do Código Tributário Nacional), prevendo a complementação da contribuição previdência do segurado empregado, nos mesmos termos do artigo mencionado alhures. Em 25 de janeiro de 2019, reiterou este entendimento ao publicar a instrução normativa $n^{\circ} 1867$, que alterou a instrução normativa RFB n 971 de 13 de novembro de 2009, prevendo que o segurado empregado intermitente poderá fazer a complementação até o piso mínimo legal, caso queira que o mês seja contabilizado para fins de aposentadoria.

1 Dispõe sobre a contribuição previdenciária complementar prevista no $\$ 1^{\circ}$ do art. 911-A da Consolidação das Leis do Trabalho (CLT), aprovada pelo Decreto-Lei ${ }^{\circ}$ 5.452, de $1^{\circ}$ de maio de 1943. O SECRETÁRIO DA RECEITA FEDERAL DO BRASIL, no uso da atribuição que lhe confere o inciso XXV do art. 327 do Regimento Interno da Secretaria da Receita Federal do Brasil, aprovado pela Portaria MF $\mathrm{n}^{\circ}$ 430, de 9 de outubro de 2017, e tendo em vista o disposto no art. 911-A da Consolidação das Leis do Trabalho (CLT), aprovada pelo Decreto-Lei $n^{\circ} 5.452$, de $1^{\circ}$ de maio de 1943, declara:

Art. $1^{\circ}$ A contribuição previdenciária complementar prevista no $\S 1^{\circ}$ do art. 911-A da Consolidação das Leis do Trabalho (CLT), aprovada pelo Decreto-Lei ${ }^{\circ}$ 5.452, de $1^{\circ}$ de maio de 1943, a ser recolhida pelo segurado empregado que receber no mês, de um ou mais empregadores, remuneração inferior ao salário mínimo mensal, será calculada mediante aplicação da alíquota de $8 \%$ (oito por cento) sobre a diferença entre a remuneração recebida e o valor do salário mínimo mensal.

$\S 1^{\circ} \mathrm{O}$ recolhimento da contribuição previdenciária prevista no caput deverá ser efetuado pelo próprio segurado até o dia 20 (vinte) do mês seguinte ao da prestação do serviço.

$\S 2^{\circ}$ Não será computado como tempo de contribuição para fins previdenciários, inclusive para manutenção da condição de segurado do Regime Geral de Previdência Social (RGPS) e cumprimento de prazo de carência para concessão de benefícios previdenciários, o mês em que a remuneração recebida pelo segurado tenha sido inferior ao salário mínimo mensal e não tenha sido efetuado o recolhimento da contribuição previdenciária complementar prevista no caput. JORGE ANTONIO DEHER RACHID 
Nesta sequência, é importante ressaltar que em casos de contrato de trabalho regidos pela CLT o empregador tem a obrigação de descontar a contribuição previdenciária de seu empregado e repassar aos cofres públicos, como afirma SANTOS (2014).

Tal entendimento coaduna com o artigo $452, \S 8^{\circ}$ da CLT, criado pela Lei $n^{\circ}$ 13.467/17:

§ 8o O empregador efetuará o recolhimento da contribuição previdenciária e o depósito do Fundo de Garantia do Tempo de Serviço, na forma da lei, com base nos valores pagos no período mensal e fornecerá ao empregado comprovante do cumprimento dessas obrigações. (BRASIL, 1943).

No entanto, é muito comum o segurado empregado descobrir quando pede algum benefício, que seu antigo empregador não recolheu as contribuições que foram descontadas durante o contrato de trabalho, razão pela qual o artigo 34, inciso I da Lei 8.213/91, prevê a presunção de recolhimento apenas com a comprovação do vínculo empregatício em benefício do segurado empregado, como segue:

Art. 34. No cálculo do valor da renda mensal do benefício, inclusive o decorrente de acidente do trabalho, serão computados: Redação dada pela Lei Complementar n ${ }^{\circ}$ 150, de 2015

I - para o segurado empregado, inclusive o doméstico, e o trabalhador avulso, os salários de contribuição referentes aos meses de contribuições devidas, ainda que não recolhidas pela empresa ou pelo empregador doméstico, sem prejuízo da respectiva cobrança e da aplicação das penalidades cabíveis, observado o disposto no $§ 5$ o do art. 29-A. (BRASIL, 1991).

O trabalho intermitente é uma grande novidade no direito brasileiro, o que fica ainda mais evidente quando se analisa a legislação supra que prevê a presunção de recolhimento e por via de consequência presume-se, a existência de atividade remunerada com a simples apresentação da carteira de trabalho (CTPS), o que é totalmente inaplicável ao segurado empregado intermitente, posto que para este o vínculo de emprego registrado em CTPS não representa efetivo exercício de atividade e recebimento de remuneração.

É possível concluir, portanto, que o trabalho intermitente, da forma em que está posto no ordenamento jurídico, distancia o segurado empregado intermitente do segurado empregado que se ativa em outros contratos de trabalho, já que algumas normas não poderão ser aplicadas a ele, ferindo, deste modo, o princípio constitucional da uniformidade e equivalência de prestações entre as populações urbana e rural (art. 194, § único, inciso II da CRFB/88) e o princípio da igualdade (Art. $7^{\circ}$, inciso XXXI da CRFB/88 e Art. 461 da CLT). 


\section{CONSIDERAÇÕES FINAIS}

O trabalho intermitente foi criado pela nova legislação sob o argumento de legalizar relações de emprego que estavam à margem da legislação trabalhista.

Dentre suas especificações o que o mais diferencia dos demais contratos de trabalho é o período de inatividade do empregado (sem que este período seja considerado tempo à disposição do empregador) e a possibilidade de remuneração mensal menor que o mínimo mensal (ou igual à zero), quebrando, portanto, barreiras intransponíveis do direito do trabalho pátrio.

Neste sentido, Vólia Bonfim Cassar é incisiva ao afirmar que:

A criação de mais uma espécie de contrato de trabalho sob a denominação "contrato intermitente" visa, na verdade, autorizar a jornada móvel variada e o trabalho variável (bico), isto é, a imprevisibilidade da prestação de serviços, ferindo de morte os princípios da segurança jurídica e a proteção ao trabalhador. A proposta de alteração legislativa só atende aos interesses dos empresários e não dos trabalhadores. (CASSAR, 2018).

Considerando esses dois fatores como pontos de partida, foi possível concluir que o segurado empregado intermitente sofrerá certa diferenciação dos demais segurados empregados, o que não poderia acontecer, visto que afronta o preceito constitucional da uniformidade de prestações previdenciárias, bem como por afastar o direito previdenciário de sua grande finalidade, que é garantir aos seus beneficiários meios necessários para a manutenção de sua subsistência, garantia que poderá faltar ao segurado empregado intermitente.

Conclui-se dessa forma porque nos períodos de inatividade o segurado empregado intermitente entrará inevitavelmente no chamado período de graça por ausência de contribuições previdenciárias e considerando que não há por ora limitação na lei sobre o período em que o empregador poderá ficar sem convocar o empregado, este estará correndo risco de perder sua qualidade de segurado por decurso do período de graça, bem como de ter prestações previdenciárias negadas pelo INSS por ausência de contribuições (mesmo estando com o contrato de trabalho ativo).

Quando se fala em carência o problema persiste, pois a legislação pertinente não garante ao empregado uma atividade mensal, tampouco remuneração mensal compatível com o salário mínimo e nem sequer o salário mínimo mensal, acarretando a obrigatoriedade de complementação de contribuições previdenciárias, considerando que o legislador já demonstrou expressamente, por intermédio do art. 911-A, criado pela MP n ${ }^{\circ}$ 808/2017, que sua intenção é de que o empregado complemente a contribuição previdenciária, sob pena de não utilização do período com contribuições menores que o piso previdenciário na contagem de carência e tempo de contribuição para fins de aposentadorias.

No mesmo sentido, diferenciando segurados empregados (contratos anteriormente previstos na CLT e contrato de trabalho intermitente), o trabalhador intermitente sofrerá mais um problema pela impossibilidade de utilização das regras 
do art. 34 da Lei $n^{\circ} 8.213 / 91$ - ou seja, a presunção de recolhimento de contribuições previdenciárias com base em simples comprovação de vínculo empregatício, levando-se em consideração que segundo a legislação os períodos de inatividade não serão considerados como tempo à disposição do empregador.

Sendo assim, caso o empregador não cumpra sua obrigação de recolher as contribuições previdenciárias descontadas dos empregados, existirão situações discrepantes, em que na primeira ocorrência o segurado empregado terá, em seu favor, a presunção de efetivo trabalho remunerado com a simples apresentação da carteira de trabalho. Já na segunda situação o segurado empregado intermitente terá que comprovar o vínculo empregatício com a carteira de trabalho e os períodos que efetivamente trabalhou, colocando em risco sua proteção previdenciária.

Razões pelas quais, conclui-se que ao ser criado, o trabalho intermitente gerou grandes impactos no direito previdenciário, vez que agora este ramo do direito tem um segurado empregado novo, que necessita de regulamentação específica, já que as regras existentes para o contrato de trabalho não eventual acabam por não lhe servirem ou por lhe diferenciar muito dos outros segurados, ferindo, deste modo, pilares constitucionais que estruturam a sociedade, bem como a finalidade da previdência social brasileira.

\section{REFERENNCIAS BIBLIOGRAFICAS}

BRASIL. Constituição da Republica Federativa do Brasil de 1988. Disponível em: <http:// www.planalto.gov.br/ccivil_03/constituicao/constituicaocompilado.htm> Acesso em: 06/05/2018.

Decreto-Lei ${ }^{\circ} 5.452$ de 01 de maio de 1943. Aprova a Consolidação das Leis do Trabalho. Disponível em: < http://www.planalto.gov.br/ccivil_03/decreto-lei/Del5452compilado.htm> Acesso em: 06/05/2018.

. Lei no 8.080 de 19 de setembro de 1990. 23 de abril de 2018. Dispõe sobre as condições para a promoção, proteção e recuperação da saúde, a organização e o funcionamento dos serviços correspondentes e dá outras providências. <http://www.planalto.gov.br/ ccivil_03/leis/L8080.htm>. Acesso em 07/05/2018.

. Lei no 8.213 de 24 de julho de 1991. Dispõe sobre os Planos de Benefícios da Previdência Social e dá outras providências. Disponível em: <http://www.planalto.gov.br/ ccivil_03/leis/L8213cons.htm> Acesso em: 07/01/2018.

CAMARGO, Antônio Bonival. Princípios e ideologias aplicados na relação de emprego. Bauru (SP): EDIPRO, 2000.

CASSAR, Vólia Bonfim. A Reforma Trabalhista e a autonomia da vontade do empregado. 2018. Disponível em: <http://www.lex.com.br/doutrina_27640581_A_REFORMA_TRABALHISTA_E_A_AUTONOMIA_DA_VONTADE_DO_EMPREGADO.aspx $>$ Acesso em: 15.maio.2018.

DALLEFI, Nayara Maria Silvério da Costa. ALMEIDA, Francyelle Cristina Paes. Da nova lei sobre aposentadoria especial: Pontuações sobre a segurança jurídica acerca do conceito da deficiência. Revista Jurídica Luso Brasileira. Lisboa. No 1 . Pág. 1.151/1.182, ano 4 (2018). 
DELGADO, Maurício Godinho. Curso de Direito do Trabalho. São Paulo. LTr, 2016. . DELGADO. Gabriela Neves. A reforma trabalhista no Brasil: com os comentários à Lei 13.467/2017, São Paulo, LTr, 2017.

FERNANDES, Jessika Katerine da Silva; ALMEIDA FILHO, José Marcelo Matos de. A presunção de recolhimento das contribuições previdenciárias do empregado doméstico. In: Âmbito Jurídico, Rio Grande, XX, n. 159, abr 2017.

Disponível em:

<http:/ / www.ambitojuridico.com.br/site/index.php?n_link=revista_artigos_leitura\&artigo_id=18829\&revista_caderno=25>. Acesso em: 11/05/2018.

HARADA, Kiyoshi. Natureza do Ato Declaratório Interpretativo - ADI - e seus efeitos. In: Âmbito Jurídico, Rio Grande, XIV, n. 92, set 2011. Disponível em: < http:/ / www.ambitojuridico.com.br/site/index.php?n_link=revista_artigos_leitura\&artigo_id=10326>. Acesso em: 11/05/2018.

IBRAHIM, Fábio Zambitte. Curso de Direito Previdenciário. 16 ed. Rio de Janeiro: Impetus, 2011.

LEITE, Carlos Henrique Bezerra. A reforma trabalhista (lei 13.467/2017) e a desconstitucionalização do acesso à justiça do trabalho: breves comentários sobre alguns institutos de direito processual do trabalho. Revista Direito UNIFACS - Debate Virtual, $n^{\circ} 208$, outubro de 2017.

MARTINS, Antero Arantes. PEDREIRA, Christina de Almeida. Reflexões sobre a reforma trabalhista. São Paulo: Scortecci, 2017.

MORAES, Alexandre de. Direito Constitucional. 15 ed. São Paulo: Atlas, 2004.

SANTOS, Marisa Ferreira dos. Direito Previdenciário. 10 ed. São Paulo: Saraiva, 2014.

Saraiva, 2017.

Direito Previdenciário Esquematizado. 07 ed. São Paulo:

SILVA, Homero Batista Mateus. Comentários a reforma trabalhista [Livro Eletrônico], $1^{a}$ ed., São Paulo: Editora Revista dos Tribunais, 2017. 